Research Article

\title{
Using Improved Prospect Theory to Develop a Partner Selection Method for Virtual Enterprises with Unknown Weight
}

\author{
Nina Su $\mathbb{D},{ }^{1}$ Xianqi Zhu, ${ }^{1}$ and Yunsheng Xin $\mathbb{D}^{2}$ \\ ${ }^{1}$ College of Economics and Management, Taiyuan University of Technology, Taiyuan, China \\ ${ }^{2}$ College of Mechanical Engineering, Taiyuan University of Science and Technology, Taiyuan, China \\ Correspondence should be addressed to Yunsheng Xin; xin_yunsheng@tyust.edu.cn
}

Received 3 March 2020; Revised 26 April 2020; Accepted 18 May 2020; Published 8 June 2020

Academic Editor: Stylianos Georgantzinos

Copyright (c) 2020 Nina Su et al. This is an open access article distributed under the Creative Commons Attribution License, which permits unrestricted use, distribution, and reproduction in any medium, provided the original work is properly cited.

\begin{abstract}
A "virtual enterprise" is an effective organization formed by enterprises and partners under market opportunity which can flexibly adapt to the dynamic market demand and improve the competitiveness of enterprises. To select virtual enterprise partners objectively and scientifically, this study proposes the evaluation model of the innovation resource capability of the alternative enterprises under the unknown weight. In the multigranularity hesitation fuzzy language environment, the unknown weight is solved by using fuzzy entropy theory. The risk attitude of decision-making enterprises is introduced by using the improved prospect theory and the selection of partners is comprehensively considered. Finally, a case study is presented to demonstrate the effectiveness of the proposed approach. The research intends to enable the virtual enterprise to choose the partners swiftly such that they can compensate for the shortcomings and optimize the allocation of innovation resources.
\end{abstract}

\section{Introduction}

The rapid development of technology is increasing the pace of life, which in turn elevates market demand for product integration. Enterprises should not only integrate advanced technology in professional fields, but also expand their cooperative work. They must strive to create winning upstream and downstream relationships between exploration and related technologies. Currently, China is in a critical period of economic transformation, and the external environment of enterprises is full of variables and opportunities. Within this context, enterprises tend to seek help from the outside world, and this often creates a virtual enterprise (VE) [1]. The essence of VE is the organization, formed by many heterogeneous enterprises under the guidance of the overall task determined by market opportunity. The VE disintegrates with the disappearance of market opportunity or the completion of the overall task. It has more flexibility than a general enterprise innovation alliance and can better seize market opportunities.
Simultaneously, it promotes heterogeneous and complementary partner enterprises to optimize the allocation of core resources. VE can decrease product design costs, shorten order cycle times, improve product quality, and reduce the risk of delivery delays. After over 20 years of research and development, the VE has been recognized as an important model of the multiparty use of competitive advantage in which enterprises share vital resources to respond to market demand quickly [2].

Although VE can rapidly respond to market demand, it will take a long time for a new product or technology to be widely recognized. This time lag effect is closely related to the technological operation and innovation level of the partners that make up the VE. In complex and dynamic market conditions, VEs are required to agree on a stable cooperation intention and share and deal with possible risks together [3]. Therefore, partner selection is the most critical step in the construction of a VE. Partner selection is directly related to the stability and development of a VE. The initial stage of establishing a VE is the careful selection of cooperative and 
innovative partners to prevent innovation risks effectively. It is necessary to study the partner selection of $\mathrm{VE}$, which can help a VE complete collaborative innovation with minimum cost and time.

Presently, most of the research on VE partner selection is based on the assumption of rationality. However, the essence of $\mathrm{VE}$ is to manage market emergencies, which requires high flexibility and mobility. This situation makes the decision-making system face more complex environmental factors. The psychological factors and risk attitude of decision-makers become the key factors to be considered. The traditional decision theory is unsuitable to meet actual expectations. When choosing the functional parameters of prospect theory, classical prospect theory only considers the irrationality of decision-making and does not distinguish the risk attitude of decisionmakers. By improving the prospect theory, the form of the value function of prospect theory is improved based on the utility curve, and its parameter range is extended, which can integrate the decision-maker's risk attitude into partner selection. On the other hand, although many scholars have made several considerations on the criteria system chosen by the VE partners and demonstrated its scientificity and objectivity, the calculation of its weight is affected by the subjective factors of experts or decisionmakers. In similar alternative enterprises, the solution method considering unknown weight is an accurate evaluation. To avoid the influence of subjective factors as much as possible, it is necessary to solve the unknown weight.

The structure of this paper is organized as follows. Section 2 presents a brief review of the VE partner selection, methods for VE partner selection, and fuzzy decision and fuzzy set. Section 3 establishes the criteria for VE partner selection. Section 4 proposes a multiattribute decisionmaking method that takes into account the risk attitude of decision-makers to solve decision-making problems with unknown weights and uncertain attribute values. Section 5 provides a real case study concerning the VE partner selection example to demonstrate the applicability and validity of the proposed criteria and method. Conclusions and directions for future research in the area are presented in Section 6.

\section{Literature Review}

Partner selection has received considerable attention for its significant effect on successful organization management. A considerable number of literature reviews are accomplished by various authors such as Guo et al. [4], Gan et al. [5], and Venkatesh et al. [6]. In this section, we classify the literature related to our work into three categories. The first category includes the works on VE partner selection. The second category includes the studies with a focus on the methods for VE partner selection. The final category explores the literature on the fuzzy decision and the fuzzy set. Following is the literature review of some recent representative works.
2.1. Virtual Enterprise Partner Selection. VE is a kind of organization form that can cooperate quickly to achieve certain common goals through sharing and participating in organizational behavior [7]. Despite differences in the definition of VE, all concepts focus on cooperation to explore market opportunities through integrated database systems [8]. As the establishment of a VE involves the integration of different innovation resources, many scholars devote their research to the selection criteria of VE partners. Here, it is important to note that such studies regard the VE as an innovation alliance composed of several enterprises answerable to a specific market demand [9]. Moreover, such studies mobilize the VE as a concept to support temporary alliances of manufacturing enterprises with various collaboration models [10]. $\mathrm{Hu}$ et al. propose that creating a VE involves different task orientations and that emerges in an interrelated state by agreeing to a continuous contract [11]. Accordingly, the VE is not in a fixed state, but instead in a dynamic state that allows it to maintain cooperation and interaction between multiple enterprises to adapt to the market in the best possible way, continuously. VEs have strategic objectives, maximizing flexibility and adaptability to environmental changes [12]. Because of the diversity of the organizational structure of the VE, the selection of partners, the complementarity of resources, and the correlation of core competitiveness are particularly important [13].

The partner selection criteria of VE should meet the needs of collaborative innovation goal to the maximum extent and also ensure the full integration of innovation resources owned by partner members. Therefore, partner selection should be based on the needs of innovative resources to determine specific objectives. Partner selection should consider not only the importance and scarcity of various innovation resources needed for collaborative innovation, but also the compatibility between partners.

2.2. Criteria for VE Partner Selection. As the success of a VE depends on its partners' performance and coherence, it is essential to review the existing research on the partner selection of VE. Gan et al. [5] put forward the method of partner selection under the mode of public-private cooperation and construct five evaluation criteria including construction and operation capability, risk management capability, environmental practices, business value formation, and financial capability. Hofstetter et al. [14] studied the influence of innovation competition and innovation incentive on the motivation of customer innovation. Yoon et al. [15] studied the impact of technology-based companies' restructuring of existing patent technologies on innovation opportunities in cross domain product development. According to the classification of innovation resources of alternative enterprises in the selection of supply chain partners, Lv and Qi [16] built a collaborative product innovation index system based on innovation resources that include 7 indicators and 20 subindicators. Yayavaram et al. [17] indicate that the likelihood of alliance formation 
increases when two firms are similar in domain knowledge, but differ in architectural knowledge. In addition, the influence of different knowledge domains and structures on partner selection is proposed.

However, the choice of VE partners has its own characteristics. Most of the existing partner methods are quantitative analysis, and the evaluation criteria are relatively complex; however, there are some flaws in practical application. It is a time-consuming and resource-intensive process that should be managed with care [18]. VE, as a special organization born under market opportunity, needs to build alliance in a short time. Therefore, the goal of cooperation is relatively clear, and the specific demand for partner innovation resources is also clear. In practice, the business of VE can always be divided into several relatively independent business processes or research objectives. It is assumed that every stage needs to select the alternative enterprises, and an excessively complex quantitative evaluation index system will restrict the efficiency of selection [19]; hence, it is not feasible in practical operation. VE partner selection pays more attention to the timeliness and convenience of the selection method [10]. In considering the completion time constraint, $\mathrm{Wu}$ and $\mathrm{Su}$ [20] model the partner selection problem by an IP formulation to minimize the manufacturing cost. The research framework of the existing VE partner selection indicators is relatively simple, such as the evaluation based on business process proposed by Guo et al. [4], simple indicators such as cost, cycle, trust, risk, and quality proposed by $\mathrm{Ye}$ and $\mathrm{Li}$ [21], or the main indicators such as innovation performance, cost, and estimated completion probability [22]. Crispim et al. [23] proposed a chance-constrained approach to rank alternative VE configurations in business environments with uncertainty, and vague and random information. With the gradual improvement of the evaluation method, the construction of the VE partner selection index system tends to be comprehensive. $\mathrm{Hu}$ et al. [11] proposed that the influencing factors of VE subtask partner selection include 3 criteria (10 subcriteria) of input resource value, task complexity, and risk.

In addition, VE emphasizes overall efficiency. Even if the main enterprise can select the best partner under each level of subtask, the combination of them may not be conducive to the improvement of the overall efficiency of the VE, which obviously goes against the goal of VE construction. When enterprises choose suitable VE partners, they often conduct multiple investigations to determine the final suitable objects. To reflect the needs of enterprises for partners scientifically and objectively, our study considers the main factors of partner selection and the characteristics of VE comprehensively. On this basis, this study simplifies the design of evaluation indicators and strives to consider the capabilities of partners comprehensively.

2.3. Methods for VE Partner Selection. Several works of literature are based on network analysis, fuzzy mathematics, data envelopment analysis, and multiobjective decisionmaking methods in the research of decision methods.
Hundreds of models and algorithms have been applied to optimize partner selection [20, 22, 24]. Research on the partner selection of VE involves a specific method to solve the problem of enterprise evaluation in which multicriteria decision-making (MCDM) is widely used. Analytic hierarchy process (AHP) is the most frequently used MCDM approach for both supplier selection in supply chain management and VE partner selection [25]. Technique for Order of Preference by Similarity to Ideal Solution (TOPSIS) proposed by Hwang and Yoon is a technique based on the similarity of ideal solutions. TOPSIS is based on the view that the selected scheme should be the closest to the "positive ideal solution" and farthest away from the "negative ideal solution" [26]. Notably, deviation degree-based and risk factor-based TOPSIS are two extended models for group decision-making proposed by $\mathrm{Ye}$ and $\mathrm{Li}$ [21]. Cost, time, trust, risk, and quality were selected as the evaluation criteria. In 2010, Ye [27] proposed an extended TOPSIS for group decision-making with interval-valued intuitionistic fuzzy numbers, which is used to solve the problem of partner selection in VEs under the condition of information asymmetry. However, such solutions do not address the flexibility of enterprise collaboration and rarely consider collaboration risk, unsettling the rationality of the selection results.

The simplicity of programming encourages many scholars to use TOPSIS, the most commonly used technique to solve MCDM problems. However, TOPSIS is insufficient to provide a consistency check of judgment and preference. It can only deal with numbers, not language definition. Therefore, to apply TOPSIS to qualitative criteria, other methods must be used to quantify subjective terms. In this study, multigranular fuzzy language is used to define subjective evaluation to compensate for this deficiency. However, considering the shortcomings of AHP and TOPSIS in weight design, fuzzy entropy theory is used to calculate the weight.

It can be observed that fuzzy decision and fuzzy set have been used in decision-making methods [28, 29]. Chuu [30] proposes a procedure to assess the degree of manufacturing flexibility in a fuzzy environment by a fuzzy fusion method of linguistic information. Zhang and Chu [31] proposed a group decision-making approach, incorporating a logarithmic least-squares optimization model and a weighted least-squares optimization model to aggregate these multiformat and multigranularity linguistic judgments, and utilized fuzzy set theory to address the uncertainty in the decision-making process. Sardari et al. [32] introduced a new fuzzy decision tree methodology based on hesitant fuzzy sets to classify highly imbalanced datasets and proved that the proposed methods outperform the other fuzzy rule-based approaches on the basis of experimental results. Rabcan et al. [33] proposed a new algorithm with the application of a fuzzy classifier for signal classification and added a new procedure of fuzzification into the preliminary transformation using a fuzzy decision tree for classification. To address the sustainable supplier selection problem, Tirkolaee et al. [34] implemented a novel hybrid approach 
based on the fuzzy logic in designing a supply chain and applied the fuzzy Decision-Making Trial and Evaluation Laboratory (DEMATEL) to identify the relationships among the main criteria. Dinçer et al. [35] analyzed the dimensions and criteria by multiple criteria decision methods with hesitant fuzzy sets to evaluate the performance results of European energy investment policies. Büyüközkan and Güleryüz [36] proposed a combined intuitionistic fuzzy group decision-making model to select the company to cooperate with potential partners in the process of product development, which is composed of an intuitionistic fuzzy analytic hierarchy process and intuitionistic fuzzy technology. Liu et al. [37] proposed a new method combined with rough number, best-worst MCDM method, and compromise ranking method (VIKOR).

However, inevitably, a lot of fuzzy and uncertain information is included in the process of determining the criteria weight, and it is difficult for traditional methods to represent the opinions of decision-making members accurately. This study focuses on limited information to determine the weight of key indicators. To deal with incomplete information effectively, decision-making members often directly use "important," "general," or "unimportant" language to reflect their opinions. Therefore, this study proposes to solve the unknown weight in the multigranularity hesitation fuzzy language environment, and on this basis, combined with the risk attitude of decision-making members, to screen the VE partners. This not only fully reflects the fuzziness of evaluation judgment, but also gives full play to the individual initiative of decision-making members.

These methods provide a good research basis for this study. Therefore, to avoid the limitation of subjective judgment on the weight, this study proposes a multiattribute decision-making method that considers the risk attitude of decision-makers to solve decision-making problems with unknown weights and uncertain attribute values. Multigranular language was used to build the evaluation criteria system of VE partners and to avoid experts' subjective preference for the criteria set. Additionally, a method of entropy weight, based on hesitation fuzzy entropy, was used to determine the attribute weight. Considering the different risk preferences of decision-makers, we transformed the fuzzy decision matrix into a prospect value matrix by using the improved prospect theory value function. We also replaced relative closeness with the calculated profit-loss ratio to rank the alternatives. Finally, a case study was used to evaluate the impact of different types of partners on the collaborative innovation efficiency of VEs to optimize resource allocation and give full play to the collaborative ability of VE.

\section{Proposed Criteria}

When enterprises choose suitable VE partners, they determine the final suitable objects through multiparty investigation. For the virtual enterprise, because of its clear market orientation and clear technical requirements, the evaluation index should be clear, easy to quantify, and easy to operate. At the same time, the amount of indicators should not be too large to build the organization in a short time [19]. Due to the complementarity of external resources in different degrees, it has a positive effect on different types of innovation [38]. As the complementarity of innovation resources involves all aspects of external resources, it needs a longer period of investigation when it is measured as a single indicator. At the same time, it is inevitable that there is incomplete information. Instead, asset complementarity and technology complementarity are considered in the indicator system. Asset complementarity can be reflected by human resources, hardware conditions, financial investment, management organization, and other indicators. Technology complementarity can be reflected by technology stock, number of patents in the target field, and the degree of technology overlap.

To scientifically and objectively reflect the needs enterprises require potential partners to fill, we constructed evaluation criteria of innovation resources, including human resources, innovation input, technical resources, and organizational culture of members, through interviews and investigation. Based on existing technological innovation indicators [39], the evaluation criteria system comprises 4 main criteria and 12 subcriteria, as shown in Table 1.

3.1. Human Resources $C_{1}$. The level and experience of technical personnel reflect the independent innovation ability of an enterprise as a single member, and the communication ability of employees reflects the degree of member matching and harmony after cooperation. Due to the imperceptible influence of each member's corporate culture, many differences exist across partners before they form a VE [44]. Notably, if partners have decent communication abilities, they can effectively negotiate differences. In addition to communication ability, the incentive strength of enterprises will also have an impact on the enthusiasm of employees' innovation [41]. On the one hand, the innovation incentive of enterprises shows the importance of innovation, and on the other hand, it also shows the enthusiasm of technical staff for innovation.

3.2. Innovation Investment $C_{2}$. Human resources are the "soft power" of innovation investment, while equipment, facilities, and investment amount are the "hard powers" behind VEs. In the actual input process, we should not only consider the amount of investment, but also plan for the advanced and matching degrees of existing hardware and equipment to optimize the allocation of resources.

3.3. Technical Resources $C_{3}$. In addition to sharing resources, the partners of a VE need to exchange and communicate about their knowledge reserves and share key technologies and related achievements [43]. Once technologies and/or patents of different partners form upstream and downstream relationships or facilitate technology 
TABle 1: Criteria for VE partner selection.

\begin{tabular}{|c|c|c|c|}
\hline & Main criteria & Subcriteria & The source literature \\
\hline \multirow{11}{*}{$\begin{array}{l}\text { Product innovation } \\
\text { resources }\end{array}$} & \multirow{4}{*}{$C_{1}$ : human resources } & $\begin{array}{c}C_{11}: \text { the level and experience of } \\
\text { technicians }\end{array}$ & Gan et al. [5], Lv and Qi [16] \\
\hline & & $C_{12}$ : communication skills of employees & $\begin{array}{l}\text { Ye and Li [21], Mun et al. [10], Naveh [40], } \\
\text { Rangus and Černe [41] }\end{array}$ \\
\hline & & $C_{13}:$ innovation incentives & Hofstetter et al. [14], Rangus and Černe [41] \\
\hline & & $\begin{array}{c}C_{21} \text { : applicability and advanced nature } \\
\text { of facilities }\end{array}$ & Lv and Qi [16] \\
\hline & \multirow{3}{*}{$C_{2}$ : innovation input } & $\begin{array}{l}C_{22}: \text { management capacity of } \\
\text { equipment and facilities }\end{array}$ & Lv and Qi [16], Wu and Su [20], Tan et al. [42] \\
\hline & & $C_{23}$ : innovation investment amount & $\begin{array}{l}\text { Lu et al. [3], Gan et al. [5], Ye and Li [21], Lp } \\
\text { et al. [24] }\end{array}$ \\
\hline & & $\begin{array}{c}C_{24}: \text { ability to manage innovation } \\
\text { investment }\end{array}$ & Guo et al. [4], Hu et al. [11], Tan et al. [42] \\
\hline & \multirow{3}{*}{$\begin{array}{l}C_{3}: \text { technology } \\
\quad \text { resources }\end{array}$} & $\begin{array}{c}C_{31}: \text { number of patents and industry } \\
\text { standards }\end{array}$ & $\begin{array}{l}\text { Gan et al. [5], Yoon et al. [15], Crispim et al. } \\
\text { [23] }\end{array}$ \\
\hline & & $\begin{array}{c}C_{32}: \text { product innovation achievements } \\
\text { in the field }\end{array}$ & Lv and Qi [16], Sköld and Karlsson [43] \\
\hline & & $C_{33}:$ the degree of technology overlap & $\begin{array}{c}\text { Hu et al. [11], Yoon et al. [15], Sköld and } \\
\text { Karlsson [43], Naveh [40] }\end{array}$ \\
\hline & $\begin{array}{l}C_{4}: \text { organization and } \\
\text { culture }\end{array}$ & $\begin{array}{c}C_{41}: \text { conflict resolution ability } \\
C_{42}: \text { product innovation atmosphere }\end{array}$ & $\begin{array}{l}\text { Lu et al. [3], Ye and } \mathrm{Li} \text { [21] } \\
\text { Mun et al. [10], Hofstetter et al. [14] }\end{array}$ \\
\hline
\end{tabular}

expansion, the VE can make full use of the minimum innovation cost to break through existing technical problems. At the same time, if the overlapping intellectual cost of similar or replaceable technology is high, the effect of partners learning from each other will be low [40].

3.4. Organizational Culture $C_{4}$. VEs have the ability to deal with the market flexibly. To maintain a VE's benign operation, a good atmosphere of innovation is essential. However, technological innovation is often uncertain, with every small decision involving potential risks. Established VEs should have a clear awareness of how to avoid innovation risks and a good ability to coordinate and solve possible conflicts-these elements include not only the full sharing of information and effective implementation among enterprises, but also intimacy and trust between partners.

\section{Methodology}

4.1. Establishment of Evaluation Grade Set for Partner Selection in VE. The first step is to determine the main criteria and subcriteria for the VE partner selection. In Section 3, four main criteria and 12 subcriteria (Table 1) have been compiled through relevant literature and the investigation of managers and practitioners. Finally, a hierarchical structure is constructed based on the partner selection criteria in the VE. According to Table 1, a standard set can be established: $C=\left\{C_{11}, C_{12}, C_{13}, C_{21}, C_{22}, C_{23}, C_{24}, C_{31}, C_{32}, C_{33}, C_{41}, C_{42}\right\}$.

Multigranularity fuzzy language is used to evaluate the criteria and build the set of criteria's evaluation results indicated by $X^{r}$. The hesitant fuzzy language information with a granularity of $r$ can be represented by the following equation:

$$
X^{r}=\left\{x_{0}^{r}, x_{1}^{r}, x_{2}^{r}, \ldots, x_{r-1}^{r}\right\}
$$

When $r=5, X^{r}$ represents a five-level granularity language scale, expressed as $X^{5}=\left\{x_{0}^{5}, x_{1}^{5}, x_{2}^{5}, \ldots, x_{4}^{5}\right\}$, comprised of the following representative language set: \{very bad, bad, general, good, excellent\}. When $r=7, X^{r}$ represents a seven-level granularity language scale, expressed as $X^{7}=\left\{x_{0}^{7}, x_{1}^{7}, x_{2}^{7}, \ldots, x_{6}^{7}\right\}$, comprised of the following representative language set: \{extremely poor, very poor, poor, medium, good, very good, excellent $\}$. When $r=9, X^{r}$ represents a nine-level granularity language scale, expressed as $X^{9}=\left\{x_{0}^{9}, x_{1}^{9}, x_{2}^{9}, \ldots, x_{8}^{9}\right\}$, comprised of the following representative language set: \{absolute difference, extreme difference, difference, medium difference, medium, medium good, good, excellent, absolutely good\}.

4.2. Construction of Multigranular Hesitation Fuzzy Model. Hesitant fuzzy linguistic term set (HFLTS) is a technology that is useful in dealing with decision-making problems in which people are hesitant to provide linguistic assessments [45]. Suppose a hesitant fuzzy multiattribute decision event involves a scheme set of $X=\left\{x_{i}\right\}$, $(i=1,2, \ldots, p)$ that contains $p$ alternatives and an attribute set of $C=\left\{c_{j}\right\}, \quad(j=1,2, \ldots, q)$ that contains $q$ evaluation attributes. Due to the complexity and uncertainty of the decision, its weight, $\omega=\left\{\omega_{1}, \omega_{2}, \ldots, \omega_{p}\right\}$, is unknown and satisfies $\omega_{j} \in[0,1],(j=1,2, \ldots, q)$ and $\sum_{j=1}^{q} \omega_{j}=1$. As a person with limited rationality, the decision-maker of the project is affected by their knowledge, background, and familiarity. Some attribute evaluation values are inevitably underconsidered. Using a hesitant fuzzy set, the decision value $H_{i j}$, given by the decisionmaker, is as follows:

$$
\mathbf{H}_{i j}=H\left[X_{i j}^{l_{i j}}\right]_{q \times p}, \quad(i=1,2, \ldots, p ; j=1,2, \ldots, q) .
$$


Here, $\mathbf{H}_{i j}$ is the evaluation result of the $j^{\text {th }}$ criteria of the $i^{\text {th }}$ enterprise. Each criteria result contains a hesitation fuzzy set. $l_{i j}$ is the number of elements in $\mathbf{H}_{i j}$, and $X_{i j}^{l_{i j}}$ is the fuzzy evaluation result.

If an enterprise chooses the most suitable partner from a series of solutions, then it can describe the attributes of the partner based on the data collected or expert opinions captured, using fine-grained hesitant fuzzy language terms. This information can be represented by a set of terms in a multigranular hesitating fuzzy language, as shown in the following equation:

$$
\mathbf{H}_{i j}=\left[\begin{array}{cccc}
H_{x_{1}}^{11} & H_{x_{2}}^{21} & \cdots & H_{x_{p}}^{p 1} \\
H_{x_{1}}^{12} & H_{x_{2}}^{22} & \cdots & H_{x_{p}}^{p 2} \\
\vdots & \vdots & \ddots & \vdots \\
H_{x_{1}}^{1 q} & H_{x_{2}}^{2 q} & \cdots & H_{x_{p}}^{p q}
\end{array}\right]_{q \times p}
$$

Here, $\mathbf{H}_{i j}$ is the hesitant fuzzy number matrix, $H_{i}$ is the $i^{\text {th }}$ scheme using the granularity of hesitant fuzzy language, and $\mathbf{H}_{X_{i}}^{i j}=\left\{X^{i j} \mid X^{i j} \in H_{i}\right\}$ is a multigranular hesitant fuzzy language term set.
4.3. Calculation of Weight by the Hesitant Fuzzy Entropy Weight Method. With the increasing complexity of social and economic problems, scholars have become aware of the unique and differing limitations of each person's thinking ability and knowledge level. Accordingly, the traditional fuzzy set proposed by Zadeh [46] has been unable to describe the information of the decision-making problems studied adequately. Due to the complexity of innovation activities, the uncertainty of technology sharing, and the limitations of experts' cognitions, academics remain focused on determining attribute weight. To ensure objective and scientific results, this study uses the method of hesitant fuzzy entropy weight to calculate multiattribute weight [47]. Under the constraint condition of interval intuitionistic fuzzy problems, a completely attribute weight can be calculated using information entropy.

The calculation method of multigranular hesitation fuzzy entropy is shown in the following equation:

$$
E(H)=-\frac{1}{L \ln 2} \sum_{m=1}^{L}\left[\begin{array}{l}
\frac{X^{\rho(m)}+X^{\rho(L-m+1)}}{2 k} \cdot \ln \frac{X^{\rho(m)}+X^{\rho(L-m+1)}}{2 k} \\
+\left(1-\frac{X^{\rho(m)}+X^{\rho(L-m+1)}}{2 k}\right) \cdot \ln \left(1-\frac{X^{\rho(m)}+X^{\rho(L-m+1)}}{2 k}\right)
\end{array}\right]
$$

When the fuzzy language set of a criteria evaluation of an enterprise is $\left\{X^{\rho(m)}, \ldots, X^{\rho(L-m+1)}\right\}$, the expected value is $E(H) . X^{\rho(m)}$ is the $m^{\text {th }}$ largest element in the hesitant fuzzy number $X$, where $m=1,2, \ldots, L$. $L$ is the level of granularity for an attribute evaluation of the scheme, $\rho(m)$ is an attribute size sequence number, and $k$ is aggregate granularity.

Based on the definition of fuzzy entropy, the value of entropy $E_{j}$ of each evaluation criterion can be calculated using the following equation:

$$
E_{j}=\frac{1}{p} \sum_{i=1}^{p}(1-E(H)) .
$$

According to the theory of information entropy, the smaller the entropy value, the higher the importance of the corresponding evaluation criteria, with the converse also being true. Therefore, the entropy weight calculation method shown in equation (6) solves for the entropy value of the $j^{\text {th }}$ evaluation criteria and evaluates its importance:

$$
\omega_{j}=\frac{1-E_{j}}{\sum_{j=1}^{q}\left(1-E_{j}\right)} .
$$

Considering the different preferences of the decisionmaker and the criteria set, and further modifying the entropy weight, $\delta_{j}(j=1,2, \ldots, q)$, may render the entropy weight of each evaluation criteria more accurate. The calculation method is shown in the following equation:

$$
\omega_{j}^{*}=\frac{\delta_{j} \omega_{j}}{\sum_{j=1}^{q} \delta_{j} \omega_{j}}, \quad j=1,2, \ldots, q .
$$

Therefore, according to equations (3) and (7), the evaluation matrix $\bar{X}^{*}$ of alternative enterprises can be obtained. The specific calculation is as follows:

$$
\bar{X}^{*}=\omega_{j}^{*} \mathbf{H}_{i j}, \quad(i=1,2, \ldots, p ; j=1,2, \ldots, q) .
$$

\subsection{Calculation of Multigranular Language Scaling and Generalized Distance}

4.4.1. Calculation of Positive and Negative Ideal Solutions. In the hesitant fuzzy set, the positive and negative ideal solutions are the sets of the maximum and minimum evaluation values in each index, respectively. The positive 
ideal solution $\mathrm{H}^{+}$, negative ideal solution $\mathrm{H}^{-}$, and calculation methods are as follows:

$$
\begin{aligned}
H^{+} & =\left\{\left\{X_{j}, \max _{i=1}^{p}\left\langle X_{i j}^{\varepsilon}\right\rangle \mid j \in J_{1}, \varepsilon \in[1, L]\right\},\left\{X_{j}, \min _{i=1}^{p}\left\langle X_{i j}^{\varepsilon}\right\rangle \mid j \in J_{2}, \varepsilon \in[1, L]\right\}\right\} \\
& =\left\{X_{j}, H\left\{\left(X_{i j}^{1}\right)^{+},\left(X_{i j}^{2}\right)^{+}, \ldots,\left(X_{i j}^{L}\right)^{+}\right\}\right\},\left\{X_{j}, H\left\{\left(X_{i j}^{1}\right)^{-},\left(X_{i j}^{2}\right)^{-}, \ldots,\left(X_{i j}^{L}\right)^{-}\right\}\right\}, \\
H^{-} & =\left\{\left\{X_{j}, \min _{i=1}^{p}\left\langle X_{i j}^{\varepsilon}\right\rangle \mid j \in J_{1}, \varepsilon \in[1, L]\right\},\left\{z_{j}, \max _{i=1}^{p}\left\langle X_{i j}^{\varepsilon}\right\rangle \mid j \in J_{2}, \varepsilon \in[1, L]\right\}\right\} \\
& =\left\{X_{j}, H\left\{\left(X_{i j}^{1}\right)^{-},\left(X_{i j}^{2}\right)^{-}, \ldots,\left(X_{i j}^{L}\right)^{-}\right\}\right\},\left\{X_{j}, H\left\{\left(X_{i j}^{1}\right)^{+},\left(X_{i j}^{2}\right)^{+}, \ldots,\left(X_{i j}^{L}\right)^{+}\right\}\right\} .
\end{aligned}
$$

Here, $J_{1}$ is the benefit criteria, $J_{2}$ is the cost criteria, $i=1,2, \ldots, p, j=1,2, \ldots, q, \varepsilon=1,2, \ldots, L$, and $X_{j}$ is the ideal solution of the $j^{\text {th }}$ attribute of the scheme.

4.4.2. Calculation Method of Multigranular Generalized Distance. Suppose the two sets of multigranular languages are $X=\left\{x_{1}, x_{2}, \ldots, x_{p}\right\},(i=1,2, \ldots, p)$ and $X^{\prime}=\left\{x_{1}, x_{2}\right.$, $\left.\ldots, x_{p^{\prime}}\right\},\left(i=1,2, \ldots, p^{\prime}\right)$. The granularity of sets $X$ and $X^{\prime}$ is $p$ and $p^{\prime}$, respectively. Suppose $H_{X}^{M}\left(x_{i}\right)=\left\{\rho_{j}^{M}\left(x_{i}\right) \mid\right.$ $\left.\rho_{j}^{M}\left(x_{i}\right) \in X\right\}$ and $H_{X^{\prime}}^{M}\left(x_{i}\right)=\left\{\rho_{j}^{M}\left(x_{i}\right) \mid \rho_{j}^{M}\left(x_{i}\right) \in X^{\prime}\right\}$ are the hesitant fuzzy sets defined with $X=\left\{x_{1}, x_{2}\right.$, $\left.\ldots, x_{p}\right\},(i=1,2, \ldots, p)$. According to Hamming distance and Euclidean distance, the $i^{\text {th }}$ attribute distance of fuzzy sets $H_{X}^{M}$ and $H_{X^{\prime}}^{M}$ is shown in equations (11) and (12), respectively:

$$
\begin{aligned}
D_{h m}\left(H_{X}^{M}, H_{X^{\prime}}^{M}\right) & =\frac{1}{L} \sum_{j=1}^{L}\left|\frac{\rho_{j}^{M}\left(x_{i}\right)}{p}-\frac{\rho_{j}^{N}\left(x_{i}\right)}{p^{\prime}}\right| \\
D_{l d}\left(H_{X}^{M}, H_{X^{\prime}}^{M}\right) & =\sqrt{\frac{1}{L} \sum_{j=1}^{L}\left(\frac{\rho_{j}^{M}\left(x_{i}\right)}{p}-\frac{\rho_{j}^{N}\left(x_{i}\right)}{p^{\prime}}\right)^{2}},
\end{aligned}
$$

where $j$ is the element sequence number of the first attribute in the hesitant fuzzy set and $j=1,2, \ldots, L . L$ is the number of elements in the attribute $x_{i}$ and $\rho_{j}^{M}\left(x_{i}\right)$ is the $j^{\text {th }}$ largest element in the attribute $x_{i}$.

Based on Hamming distance and Euclid distance, the general expression of two kinds of distances can be obtained by extending the hesitant fuzzy distance. The calculation method of the distance $D_{T}\left(H_{X}^{M}, H_{X^{\prime}}^{N}\right)$ between the fuzzy set $H_{X}^{M}$ and $H_{X^{\prime}}^{N}$ is shown in the following equation:

$$
D_{T}\left(H_{X}^{M}, H_{X^{\prime}}^{N}\right)=\left[\frac{1}{L} \sum_{j=1}^{L}\left|\frac{\rho_{j}^{M}\left(x_{i}\right)}{p}-\frac{\rho_{j}^{N}\left(x_{i}\right)}{p^{\prime}}\right|^{\chi}\right]^{1 / \chi},
$$

where $\chi$ is a positive integer and $D_{T}\left(H_{X}^{M}, H_{X^{\prime}}^{N}\right)$ is the distance between two fuzzy sets.

The distance between scheme $z_{i}$ and positive and negative ideal solutions is, thus, expressed by $D_{T}^{+}\left(H_{i}, H^{+}\right)$and $D_{T}^{-}\left(H_{i}, H^{-}\right)$, respectively, as shown in equations (14) and (15), respectively:

$$
\begin{aligned}
& D_{T}^{+}\left(H_{i}, H^{+}\right)=\left\{D_{T}\left(H_{i 1}, H_{1}^{+}\right), D_{T}\left(H_{i 2}, H_{2}^{+}\right), \ldots, D_{T}\left(H_{i q}, H_{q}^{+}\right)\right\}, \quad i=1,2, \ldots, p, \\
& D_{T}^{-}\left(H_{i}, H^{-}\right)=\left\{D_{T}\left(H_{i 1}, H_{1}^{-}\right), D_{T}\left(H_{i 2}, H_{2}^{-}\right), \ldots, D_{T}\left(H_{i q}, H_{q}^{-}\right)\right\}, \quad i=1,2, \ldots, p,
\end{aligned}
$$

\subsection{Ranking Method Based on Prospect Theory}

4.5.1. Improved Prospect Theory. Prospect theory assumes bounded rationality. It, thus, divides the human decisionmaking process into two main stages: (1) the collection of the evaluation objects or the value of the evaluation scheme under different criteria and (2) decisions after the information is synthesized based on the collected decision matrix.
Therefore, to consider the risk attitude and behavioral characteristics of decision-makers, prospect theory uses "foreground value" instead of expected utility as the basis for decision-making. It is, thus, summarized as a descriptive decision model. Prospect theory reveals the influence of subconscious psychology on decision-making results and promotes the continuous improvement of decision-making theory [48]. The reference point is an important parameter 
to measure profit and loss. Thus, choosing a reasonable reference point in prospect theory influences decisionmaking results [49]. In this study, positive and negative ideal solutions are used as reference points [50].

The value function proposed by Tversky and Kahneman [51] is the value of the decision-maker's subjective feelings based on actual benefits and losses. The prospect value of decision-makers in prospect theory includes two parts: (1) the value function and (2) the weight function. The calculation method is shown in the following equation:

$$
V=\sum_{i=0}^{n} \omega\left(p_{i}\right) v\left(\Delta x_{i}\right) .
$$

Here, $V$ is the prospect value, $v\left(\Delta x_{i}\right)$ is the value function, and $\omega\left(p_{i}\right)$ is the weight function.

The concept of the utility curve was first put forward by Bernoulli [52]. It shows the decision-maker's reflection on profit-loss in the face of risk. Generally, the risk attitude of decision-makers is fitted into a curve to measure subjective attitude. Based on the utility function proposed by Bernoulli, we introduce a new parameter based on the utility curve to render the relative loss of income more sensitive [53]. The expression of the value function of the improved prospect theory is shown in the following equation:

$$
v(\Delta x)= \begin{cases}\varphi \Delta x^{\alpha}, & \Delta x \geq 0, \\ -\theta(-\Delta x)^{\beta}, & \Delta x<0,\end{cases}
$$

where $\Delta x$ is the distance from the reference point, $\Delta x \geq 0$ is the benefit, $\Delta x<0$ is the loss, $\alpha$ and $\beta$ are the risk sensitivity coefficients in the case of profit or loss, $\theta$ is the risk attitude coefficient, and $\theta>1$ indicates that the decisionmaker is sensitive to the loss. Additionally, $\varphi$ and $\theta$ reflect that decision-makers are more sensitive to gains or losses. When $\theta=1$ and $\varphi>1$, earnings are more sensitive to loss, while when $\varphi=1$ and $\theta>1$, losses are more sensitive to earnings.

Zeng [54] reproduced the Tversky experiment and found that the value of the same experimental procedure in different regions with parameters $\alpha$ and $\beta$ can be greater than 1 . This phenomenon is because the experimental data did not fully meet the conditions of each country in his experiment. $\mathrm{Ma}$ and Sun [53] believe that the variance is not caused by differences between China and the United States because of the room for improvement in the parameter values. He, thus, proposed three different types of risk attitudes-conservative, intermediate, and risky. More scholars have built on this research [55]. The prospect theoretical value functions of three different risk attitudes are shown in Figure 1. This study followed decision-makers with three different types of risk attitudes-risky $(0<\alpha, \beta<1)$, intermediate $(\alpha=\beta=1)$, and conservative $(\alpha, \beta>1)$ - to design value function parameters [55].

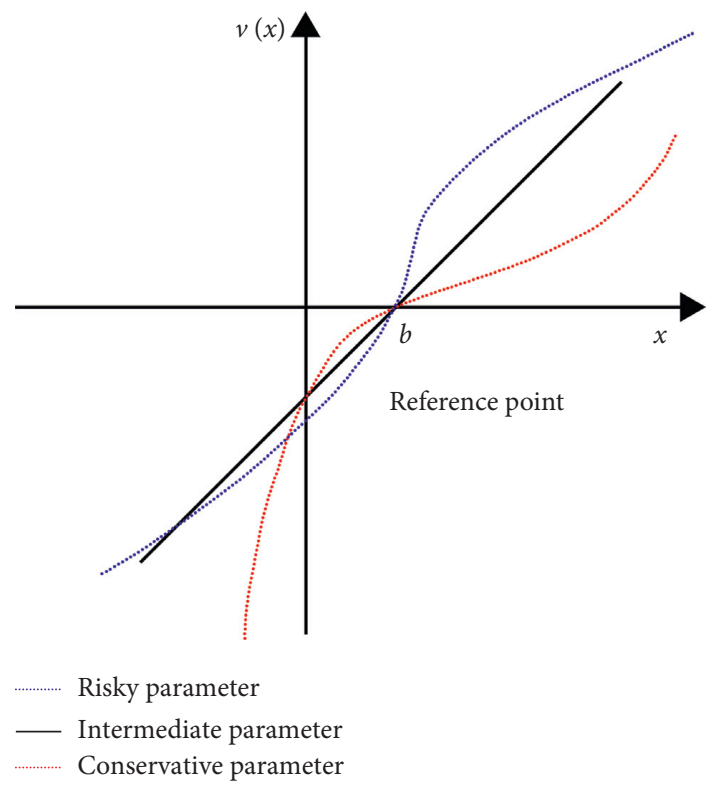

Figure 1: Prospect theoretical value function of three different risk attitudes.

4.5.2. Ranking according to Benefit-Loss Ratio. According to the concept of the value function and behavioral economics in prospect theory, each scheme's benefit-loss emerges relative to the positive ideal solution, and each scheme's benefit-gain emerges relative to the negative ideal solution. This is given by

$$
\begin{gathered}
{\left[V_{i j}^{-}\left(D_{T}\left(H_{i}, H^{+}\right)\right)\right]=\left[-\theta\left(D_{T}\left(H_{i j}, H_{j}^{+}\right)\right)^{\beta}\right]_{p \times q},} \\
{\left[V_{i j}^{+}\left(D_{T}\left(H_{i}, H^{+}\right)\right)\right]=\left[\varphi\left(D_{T}\left(H_{i j}, H_{j}^{-}\right)\right)^{\alpha}\right]_{p \times q} .}
\end{gathered}
$$

In addition to the result of the closeness degree, the benefit-loss ratio $S_{i}$ of the prospect theory can measure the advantages and disadvantages of the scheme. The larger the benefit-loss ratio $S_{i}$, the better the plan. The calculation method of the profit-loss ratio is shown in the following equation:

$$
S_{i}=\frac{\sum_{j=1}^{p} V_{i j}^{+}\left(D_{T}\left(H_{i}, H^{+}\right)\right)}{\sum_{j=1}^{p} V_{i j}^{-}\left(D_{T}\left(H_{i}, H^{+}\right)\right)} .
$$

4.6. Steps of Partner Selection in Construction Projects. To clarify the fuzzy decision-making problem of uncertain attribute weight and multigranular hesitation for VE partner evaluation, we propose the evaluation model of enterprise innovation input, ranked by the multiattribute decisionmaking method, based on the entropy weight and improved prospect theory. The evaluation process of VE partner selection is shown in Figure 2. 


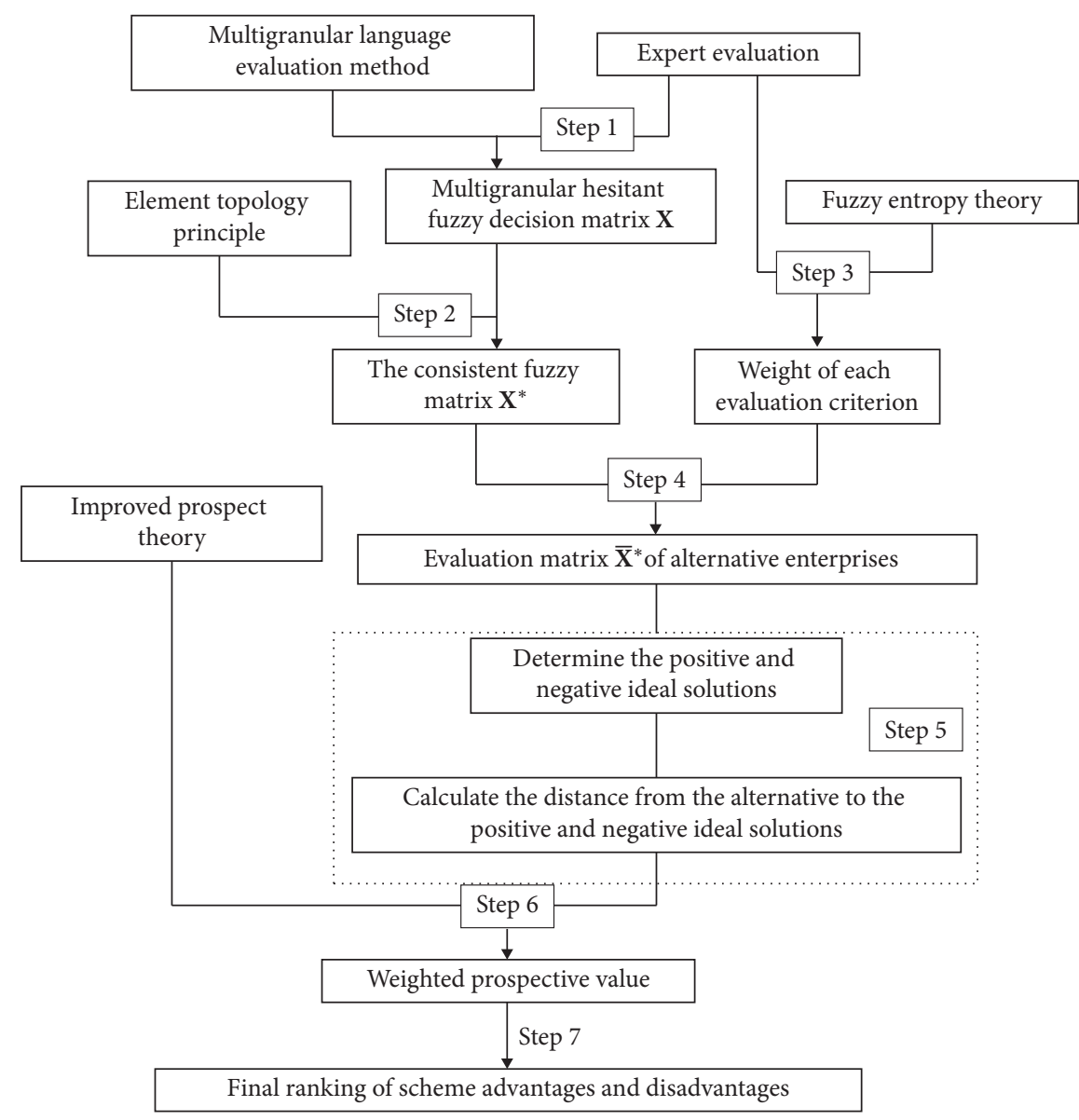

FIgURE 2: Evaluation process of VE partner selection.

Step 1: the multigranular language is used to grade the criteria system, and the standardized fuzzy decisionmaking matrix $\mathbf{X}$ is constructed according to equation (3).

Step 2: the fuzzy array elements in the evaluation matrix are arranged in increasing order, and the number of elements in the matrix is supplemented by combining them with the expansion rules to obtain the unified fuzzy decision matrix $\mathbf{X}^{*}$ of the evaluation quantity of each index.

Step 3: the concept of information entropy is applied to hesitant fuzzy theory, and the weight of the evaluation criteria is calculated by the obtained fuzzy entropy. In the case of unknown weight, more accurate weight can be obtained using equations (4) to (7).

Step 4: multiplying the weight by the unified fuzzy decision matrix $\mathbf{X}^{*}$ gives the evaluation matrix of alternative enterprises $\bar{X}^{*}$

Step 5: combining equations (9) and (10) solves for the positive and negative ideal solutions, $\mathrm{H}^{+}$and $\mathrm{H}^{-}$, respectively, of the fuzzy evaluation matrix. According to equations (14) and (15), the distance between each scheme and positive and negative ideal solutions is calculated.

Step 6: from the meaning of value function in equation (17) of prospect theory, the earnings of each scheme, relative to the reference point, can be obtained. The calculation methods of benefit-loss and gain are shown in equations (18) and (19), respectively.

Step 7: finally, the loss-profit ratio of each scheme is calculated according to equation (20), to rank the advantages and disadvantages of schemes.

\section{Case Study}

5.1. Case Company Background. In this paper, to verify the effectiveness of the decision-making model, an intelligent device manufacturer is taken as an example to illustrate the decision-making process. Assuming the manufacturer achieves a moderate scientific research result with strong practicability through continuous experiment and research, it plans to build a VE. It prepares products for sale in the market. 
In the early stage of bidding and investigation, the manufacturer is faced with selecting partners from enterprises $x_{1}, x_{2}, x_{3}$, and $x_{4}$ to build a VE. However, considering the management and profit-sharing of VE, only one or two enterprises need to be selected as partners. To explore research and development in new technology, and to scientifically consider the advantages and disadvantages of partnering with the four enterprises, experts are invited to evaluate technology-based SMEs in a province of China and use the evaluation system (Table 1) as in preceding sections for evaluation. The evaluation criteria set can be defined as $C=\left\{C_{11}, C_{12}, C_{13}, C_{21}, C_{22}, C_{23}, C_{24}\right.$, $\left.C_{31}, C_{32}, C_{33}, C_{41}, C_{42}\right\}$.

\subsection{Application of the Proposed Criteria and Method}

Step 1: the expert evaluation uses the multigranular language scaling method to yield a result for the hesitation fuzzy decision matrix, as shown in Table 2 .

Step 2: the elements in Table 2 are supplemented, and the elements in the less hesitant fuzzy number are increased using repetition or average so that all elements in the hesitant fuzzy number have the same number. Ensure that all the elements in Table 2 are expanded to match the fuzzy matrix $\mathbf{X}^{*}$ :

$$
\mathbf{X}^{*}=\left[\begin{array}{lllll}
(0.5714,0.7143,0.8571) & (0.4,0.6,0.8) & (0.3333,0.4444,0.5556) & (0.4444,0.5556,0.6667) \\
(0.4286,0.5000,0.5714) & (0.4,0.5,0.6) & (0.3333,0.4444,0.5556) & (0.6667,0.7778,0.8889) \\
(0.2857,0.4286,0.5714) & (0.8,0.8,0.8) & (0.5556,0.6111,0.6667) & (0.5556,0.6667,0.7778) \\
(0.5714,0.7143,0.8571) & (0.4,0.6,0.8) & (0.4444,0.5556,0.6667) & (0.2222,0.3333,0.4444) \\
(0.7143,0.7857,0.8571) & (0.6,0.7,0.8) & (0.2222,0.3333,0.4444) & (0.4444,0.5000,0.5556) \\
(0.5714,0.7143,0.8571) & (0.4,0.6,0.8) & (0.5556,0.5556,0.5556) & (0.5556,0.6667,0.7778) \\
(0.4286,0.5000,0.5714) & (0.2,0.4,0.6) & (0.6667,0.7778,0.8889) & (0.4444,0.4444,0.4444) \\
(0.4286,0.5000,0.5714) & (0.4,0.5,0.6) & (0.7778,0.8333,0.8889) & (0.5556,0.6111,0.6667) \\
(0.4286,0.5714,0.7143) & (0.4,0.6,0.8) & (0.5556,0.5556,0.5556) & (0.4444,0.5000,0.5556) \\
(0.4286,0.4286,0.4286) & (0.6,0.7,0.8) & (0.3333,0.4444,0.5556) & (0.2222,0.3333,0.4444) \\
(0.4286,0.5714,0.7143) & (0.2,0.4,0.6) & (0.3333,0.3333,0.3333) & (0.3333,0.3889,0.4444)
\end{array}\right] .
$$

Step 3: as this study proposes, a multiattribute decision-making method based on multigranular hesitation fuzzy entropy transformation is used to address the difficulty in determining the weights of experts and indices in the group decision-making when such weights are unknown. Next, the unknown weight was calculated using equations (4) to (7). And according to the calculation results and the decisionmaker's preference for the index, the more accurate weight $\omega^{*}$ is obtained, as shown in the following equation:

$$
\omega^{*}=[0.0815,0.1085,0.182,0.0487,0.0857,0.0487,0.1252,0.052,0.0733,0.0234,0.0994,0.0716]^{T} .
$$


Table 2: Multigranular hesitation fuzzy decision matrix.

\begin{tabular}{lccrr}
\hline & $x_{1}$ & $x_{2}$ & $x_{3}$ & $x_{4}$ \\
\hline$C_{11}$ & $\left(X_{4}^{7}, X_{5}^{7}, X_{6}^{7}\right)$ & $\left(X_{2}^{5}, X_{3}^{5}, X_{4}^{5}\right)$ & $\left(X_{3}^{9}, X_{4}^{9}, X_{5}^{9}\right)$ & $\left(X_{4}^{9}, X_{5}^{9}, X_{6}^{9}\right)$ \\
$C_{12}$ & $\left(X_{3}^{7}, X_{4}^{7}\right)$ & $\left(X_{2}^{5}, X_{3}^{5}\right)$ & $\left(X_{3}^{9}, X_{4}^{9}, X_{5}^{9}\right)$ & $\left(X_{6}^{9}, X_{7}^{9}, X_{8}^{9}\right)$ \\
$C_{13}$ & $\left(X_{4}^{5}\right)$ & $\left(X_{5}^{9}, X_{6}^{9}\right)$ & $\left(X_{5}^{9}, X_{6}^{9}, X_{7}^{9}\right)$ \\
$C_{21}$ & $\left(X_{2}^{7}, X_{3}^{7}, X_{4}^{7}\right)$ & $\left(X_{2}^{5}, X_{3}^{5}, X_{4}^{5}\right)$ & $\left(X_{2}^{9}, X_{3}^{9}, X_{6}^{9}\right)$ & $\left(X_{4}^{9}\right)$ \\
$C_{22}$ & $\left(X_{4}^{7}, X_{5}^{7}, X_{6}^{7}\right)$ & $\left(X_{3}^{5}, X_{4}^{5}\right)$ & $\left(X_{5}^{9}\right)$ & $\left(X_{4}^{9}, X_{5}^{9}\right)$ \\
$C_{23}$ & $\left(X_{5}^{7}, X_{6}^{7}\right)$ & $\left(X_{2}^{5}, X_{3}^{5}, X_{4}^{5}\right)$ & $\left(X_{8}^{9}\right)$ & $\left(X_{6}^{9}, X_{6}^{9}, X_{7}^{9}\right)$ \\
$C_{24}$ & $\left(X_{4}^{7}, X_{5}^{7}, X_{6}^{7}\right)$ & $\left(X_{2}^{5}, X_{3}^{5}\right)$ & $\left(X_{7}^{9}, X_{8}^{9}\right)$ & $\left(X_{6}^{9}, X_{7}^{9}\right)$ \\
$C_{31}$ & $\left(X_{4}^{7}\right)$ & $\left(X_{1}^{5}, X_{2}^{5}, X_{3}^{5}\right)$ & $\left(X_{5}^{9}\right)$ & $\left(X_{4}^{9}\right)$ \\
$C_{32}$ & $\left(X_{3}^{7}, X_{4}^{7}\right)$ & $\left(X_{2}^{5}, X_{3}^{5}\right)$ & $\left(X_{3}^{9}, X_{4}^{9}, X_{5}^{9}\right)$ & $\left(X_{5}^{9}, X_{6}^{9}\right)$ \\
$C_{33}$ & $\left(X_{3}^{7}, X_{4}^{7}\right)$ & $\left(X_{2}^{5}, X_{3}^{5}, X_{4}^{5}\right)$ & $\left(X_{3}^{9}\right)$ & $\left(X_{4}^{9}, X_{5}^{9}\right)$ \\
$C_{41}$ & $\left(X_{3}^{7}, X_{4}^{7}, X_{5}^{7}\right)$ & $\left(X_{3}^{7}\right)$ & $\left(X_{1}^{5}, X_{4}^{5}\right)$ & $\left(X_{2}^{5}, X_{3}^{5}\right)$ \\
$C_{42}$ & $\left(X_{3}^{7}, X_{4}^{7}, X_{5}^{7}\right)$ & & $\left(X_{3}^{9}, X_{4}^{9}\right)$ \\
\hline
\end{tabular}

Step 4: the weight matrix $\omega^{*}$ is multiplied by the normalized hesitant fuzzy matrix $\mathbf{X}^{*}$ to obtain the weighted normalized matrix $\bar{X}^{*}$ :

$$
\bar{X}^{*}=\left[\begin{array}{lllll}
(0.0466,0.0582,0.0698) & (0.0326,0.0489,0.0652) & (0.0272,0.0362,0.0453) & (0.0362,0.0453,0.0543) \\
(0.0465,0.0542,0.0620) & (0.0434,0.0542,0.0651) & (0.0362,0.0482,0.0603) & (0.0723,0.0844,0.0964) \\
(0.0520,0.0780,0.1040) & (0.1456,0.1456,0.1456) & (0.1011,0.1112,0.1213) & (0.1011,0.1213,0.1415) \\
(0.0279,0.0348,0.0418) & (0.0195,0.0292,0.0390) & (0.0217,0.0271,0.0325) & (0.0108,0.0162,0.0217) \\
(0.0612,0.0673,0.0734) & (0.0514,0.0600,0.0685) & (0.0190,0.0286,0.0381) & (0.0381,0.0428,0.0476) \\
(0.0279,0.0348,0.0418) & (0.0195,0.0292,0.0390) & (0.0271,0.0271,0.0271) & (0.0271,0.0325,0.0379) \\
(0.0716,0.0716,0.0716) & (0.0501,0.0626,0.0751) & (0.1113,0.1113,0.1113) & (0.0835,0.0904,0.0974) \\
(0.0223,0.0260,0.0297) & (0.0104,0.0208,0.0312) & (0.0347,0.0405,0.0462) & (0.0231,0.0231,0.0231) \\
(0.0314,0.0367,0.0419) & (0.0293,0.0367,0.0440) & (0.0570,0.0611,0.0652) & (0.0407,0.0448,0.0489) \\
(0.0100,0.0134,0.0167) & (0.0094,0.0140,0.0187) & (0.0130,0.0130,0.0130) & (0.0104,0.0117,0.0130) \\
(0.0426,0.0426,0.0426) & (0.0596,0.0696,0.0795) & (0.0331,0.0442,0.0552) & (0.0221,0.0331,0.0442) \\
(0.0307,0.0409,0.0511) & (0.0143,0.0286,0.0429) & (0.0239,0.0239,0.0239) & (0.0239,0.0278,0.0318)
\end{array}\right] .
$$

Step 5: the fuzzy positive ideal solution $\mathrm{H}^{+}$and negative ideal solution $\mathrm{H}^{-}$are obtained by solving equations (9) and (10), as shown in Table 3. Now, the distance $D_{T}^{+}\left(H_{i}, H^{+}\right)$between each scheme and positive ideal solution and the distance $D_{T}^{-}\left(H_{i}, H^{-}\right)$between each scheme and negative ideal solution can be determined using equations (14) and (15). According to our calculation, results are shown in Table 4.

Step 6: based on the significance of the value function in prospect theory, the positive ideal solution and negative ideal solution are the reference points for the scheme, that is, the loss value and the revenue value, respectively. Let $\alpha=\beta=0.88$ be risky parameters, $\alpha=\beta=1$ be intermediate parameters, and $\alpha=\beta=1.21$ be conservative parameters. We calculate the foreground value of each scheme according to equations (18) and (19), as shown in Tables 5-7.
Step 7: we calculate the profit-loss ratio based on the prospect theory using equation (20) and uncover the advantages and disadvantages of each scheme. The schemes were then ranked, as shown in Table 8 .

5.3. Comparative Analysis of Results. Table 8 reveals that, after using the entropy weight method, to objectively solve the weights along with three different corporate decisionmaker risk attitudes, the optimal ranked enterprise among the four companies is enterprise $x_{2}$. Choosing enterprise $x_{2}$ as a partner can effectively prevent innovation risks, allocate innovation resources, promote technology sharing among enterprises, and promote the stable growth of the VE.

Moreover, the ranking of the four enterprises was $x_{2}>x_{3}>x_{4}>x_{1}$ for risky and intermediate decision-makers and $x_{2}>x_{3}>x_{4}>x_{1}$ for conservative decision-makers. Comparing this with the normalization matrix indicates, although enterprises $x_{1}, x_{3}$, and $x_{4}$ have advantages, their 
TABLe 3: Positive and negative ideal solutions of hesitant fuzzy language.

\begin{tabular}{lcr}
\hline Evaluation criteria $(C)$ & Negative ideal solution $\left(H^{-}\right)$ & Positive ideal solution $\left(H^{+}\right)$ \\
\hline$C_{11}$ & $(0.0272,0.0362,0.0453)$ & $(0.0466,0.0582,0.0698)$ \\
$C_{12}$ & $(0.0362,0.0482,0.0603)$ & $(0.0723,0.0844,0.0964)$ \\
$C_{13}$ & $(0.0520,0.0780,0.1040)$ & $(0.1456,0.1456,0.1456)$ \\
$C_{21}$ & $(0.0108,0.0162,0.0217)$ & $(0.0279,0.0348,0.0418)$ \\
$C_{22}$ & $(0.0190,0.0286,0.0381)$ & $(0.0612,0.0673,0.0734)$ \\
$C_{23}$ & $(0.0195,0.0271,0.0271)$ & $(0.0279,0.0348,0.0418)$ \\
$C_{24}$ & $(0.0501,0.0626,0.0716)$ & $(0.1113,0.1113,0.1113)$ \\
$C_{31}$ & $(0.0104,0.0208,0.0231)$ & $(0.0347,0.0405,0.0462)$ \\
$C_{32}$ & $(0.0293,0.0367,0.0419)$ & $(0.0570,0.0611,0.0652)$ \\
$C_{33}$ & $(0.0094,0.0117,0.0130)$ & $(0.0130,0.0140,0.0187)$ \\
$C_{41}$ & $(0.0221,0.0331,0.0426)$ & $(0.0596,0.0696,0.0795)$ \\
$C_{42}$ & $(0.0143,0.0239,0.0239)$ & $(0.0307,0.0409,0.0511)$ \\
\hline
\end{tabular}

Table 4: Distance between positive and negative ideal solutions of each scheme attribute.

\begin{tabular}{|c|c|c|c|c|c|c|c|c|}
\hline \multirow{2}{*}{$\begin{array}{l}\text { Scheme } \\
\text { Criteria }\end{array}$} & \multicolumn{2}{|c|}{$x_{1}$} & \multicolumn{2}{|c|}{$x_{2}$} & \multicolumn{2}{|c|}{$x_{3}$} & \multicolumn{2}{|c|}{$x_{4}$} \\
\hline & $\begin{array}{c}\text { Positive ideal } \\
\text { solution } \\
\text { distance }\end{array}$ & $\begin{array}{c}\text { Negative ideal } \\
\text { solution } \\
\text { distance }\end{array}$ & $\begin{array}{c}\text { Positive ideal } \\
\text { solution } \\
\text { distance }\end{array}$ & $\begin{array}{c}\text { Negative ideal } \\
\text { solution } \\
\text { distance }\end{array}$ & $\begin{array}{c}\text { Positive ideal } \\
\text { solution } \\
\text { distance } \\
\end{array}$ & $\begin{array}{c}\text { Negative ideal } \\
\text { solution } \\
\text { distance }\end{array}$ & $\begin{array}{c}\text { Positive ideal } \\
\text { solution } \\
\text { distance }\end{array}$ & $\begin{array}{c}\text { Negative ideal } \\
\text { solution } \\
\text { distance }\end{array}$ \\
\hline$\overline{C_{11}}$ & 0 & 0.0221 & 0.0101 & 0.0140 & 0.0221 & 0 & 0.0131 & 0.0091 \\
\hline$C_{12}$ & 0.0303 & 0.0070 & 0.0302 & 0.0061 & 0.0362 & 0 & 0 & 0.0362 \\
\hline$C_{13}$ & 0.0708 & 0 & 0 & 0.0708 & 0.0354 & 0.0357 & 0.0293 & 0.0436 \\
\hline$C_{21}$ & 0 & 0.0186 & 0.0060 & 0.0135 & 0.0078 & 0.0108 & 0.0186 & 0 \\
\hline$C_{22}$ & 0 & 0.0388 & 0.0076 & 0.0314 & 0.0388 & 0 & 0.0245 & 0.0148 \\
\hline$C_{23}$ & 0 & 0.0107 & 0.0060 & 0.0070 & 0.0096 & 0.0044 & 0.0026 & 0.0082 \\
\hline$C_{24}$ & 0.0398 & 0.0134 & 0.0498 & 0.0021 & 0 & 0.0507 & 0.0216 & 0.0292 \\
\hline$C_{31}$ & 0.0145 & 0.0084 & 0.0200 & 0.0047 & 0 & 0.0224 & 0.0180 & 0.0075 \\
\hline$C_{32}$ & 0.0245 & 0.0012 & 0.0246 & 0.0012 & 0 & 0.0252 & 0.0163 & 0.0090 \\
\hline$C_{33}$ & 0.0021 & 0.0024 & 0.0021 & 0.0036 & 0.0034 & 0.0022 & 0.0039 & 0.0006 \\
\hline$C_{41}$ & 0.0282 & 0.0130 & 0 & 0.0370 & 0.0254 & 0.0116 & 0.0364 & 0.0009 \\
\hline$C_{42}$ & 0 & 0.0208 & 0.0127 & 0.0114 & 0.0190 & 0.0055 & 0.0140 & 0.0075 \\
\hline
\end{tabular}

TABle 5: Prospective values of attributes for risky scheme.

\begin{tabular}{|c|c|c|c|c|c|c|c|c|}
\hline \multirow{2}{*}{$\begin{array}{l}\text { Scheme } \\
\text { Criteria }\end{array}$} & \multicolumn{2}{|c|}{$x_{1}$} & \multicolumn{2}{|c|}{$x_{2}$} & \multicolumn{2}{|c|}{$x_{3}$} & \multicolumn{2}{|c|}{$x_{4}$} \\
\hline & $\begin{array}{l}\text { Positive } \\
\text { prospective } \\
\text { values }\end{array}$ & $\begin{array}{c}\text { Negative } \\
\text { prospective } \\
\text { values }\end{array}$ & $\begin{array}{c}\text { Positive } \\
\text { prospective } \\
\text { values }\end{array}$ & $\begin{array}{c}\text { Negative } \\
\text { prospective } \\
\text { values }\end{array}$ & $\begin{array}{c}\text { Positive } \\
\text { prospective } \\
\text { values }\end{array}$ & $\begin{array}{c}\text { Negative } \\
\text { prospective } \\
\text { values }\end{array}$ & $\begin{array}{c}\text { Positive } \\
\text { prospective } \\
\text { values }\end{array}$ & $\begin{array}{c}\text { Negative } \\
\text { prospective } \\
\text { values }\end{array}$ \\
\hline$\overline{C_{11}}$ & 0.0349 & 0 & 0.0233 & -0.0393 & 0 & -0.0785 & 0.0159 & -0.0496 \\
\hline$C_{12}$ & 0.0127 & -0.1038 & 0.0113 & -0.1033 & 0 & -0.1212 & 0.0539 & 0 \\
\hline$C_{13}^{12}$ & 0 & -0.2190 & 0.0973 & 0 & 0.0532 & -0.1188 & 0.0635 & -0.1008 \\
\hline$C_{21}$ & 0.0300 & 0 & 0.0226 & -0.0250 & 0.0186 & -0.0316 & 0 & -0.0676 \\
\hline$C_{22}$ & 0.0574 & 0 & 0.0476 & -0.0307 & 0 & -0.1291 & 0.0245 & -0.0860 \\
\hline$C_{23}$ & 0.0185 & 0 & 0.0127 & -0.0250 & 0.0084 & -0.0377 & 0.0147 & -0.0121 \\
\hline$C_{24}$ & 0.0225 & -0.1317 & 0.0043 & -0.1605 & 0.0725 & 0 & 0.0446 & -0.0771 \\
\hline$C_{31}$ & 0.0149 & -0.0544 & 0.0089 & -0.0720 & 0.0354 & 0 & 0.0134 & -0.0655 \\
\hline$C_{32}$ & 0.0027 & -0.0859 & 0.0027 & -0.0863 & 0.0392 & 0 & 0.0159 & -0.0601 \\
\hline$C_{33}$ & 0.0049 & -0.0099 & 0.0070 & -0.0099 & 0.0046 & -0.0150 & 0.0015 & -0.0170 \\
\hline$C_{41}$ & 0.0219 & -0.0973 & 0.0549 & 0 & 0.0198 & -0.0888 & 0.0021 & -0.1220 \\
\hline$C_{42}$ & 0.0331 & 0 & 0.0194 & -0.0483 & 0.0103 & -0.0687 & 0.0135 & -0.0527 \\
\hline
\end{tabular}

overall strength is almost the same. Meanwhile, turning the spotlight on the expert evaluation figures of enterprise $x_{3}$, we find that its technology resources are its advantage, and the rest of its innovation resources are mediocre. When the weights of traditional evaluation methods are known, this unilateral advantage may be affected by the subjective factors of experts and becomes a shortboard. In this study, fuzzy entropy is used to calculate the unknown weight, which can effectively avoid the interference of experts' subjective factors on enterprise ranking, and more objectively evaluate the advantage resources of enterprises. Using our evaluation method, we find that risk-taking and intermediate decision- 
TABLE 6: Prospective values of attributes for intermediate schemes.

\begin{tabular}{|c|c|c|c|c|c|c|c|c|}
\hline \multirow{2}{*}{$\begin{array}{l}\text { Scheme } \\
\text { Criteria }\end{array}$} & \multicolumn{2}{|c|}{$x_{1}$} & \multicolumn{2}{|c|}{$x_{2}$} & \multicolumn{2}{|c|}{$x_{3}$} & \multicolumn{2}{|c|}{$x_{4}$} \\
\hline & $\begin{array}{c}\text { Positive } \\
\text { prospective } \\
\text { values }\end{array}$ & $\begin{array}{c}\text { Negative } \\
\text { prospective } \\
\text { values }\end{array}$ & $\begin{array}{c}\text { Positive } \\
\text { prospective } \\
\text { values }\end{array}$ & $\begin{array}{c}\text { Negative } \\
\text { prospective } \\
\text { values }\end{array}$ & $\begin{array}{c}\text { Positive } \\
\text { prospective } \\
\text { values }\end{array}$ & $\begin{array}{c}\text { Negative } \\
\text { prospective } \\
\text { values }\end{array}$ & $\begin{array}{c}\text { Positive } \\
\text { prospective } \\
\text { values }\end{array}$ & $\begin{array}{c}\text { Negative } \\
\text { prospective } \\
\text { values }\end{array}$ \\
\hline$C_{11}$ & 0.0221 & 0 & 0.0140 & -0.0226 & 0 & -0.0497 & 0.0091 & -0.0295 \\
\hline$C_{12}$ & 0.0070 & -0.0683 & 0.0061 & -0.0678 & 0 & -0.0814 & 0.0362 & 0 \\
\hline$C_{13}$ & 0 & -0.1594 & 0.0708 & 0 & 0.0357 & -0.0795 & 0.0436 & -0.0660 \\
\hline$C_{21}$ & 0.0186 & 0 & 0.0135 & -0.0135 & 0.0108 & -0.0176 & 0 & -0.0419 \\
\hline$C_{22}$ & 0.0388 & 0 & 0.0314 & -0.0171 & 0 & -0.0874 & 0.0148 & -0.0551 \\
\hline$C_{23}$ & 0.0107 & 0 & 0.0070 & -0.0135 & 0.0044 & -0.0216 & 0.0082 & -0.0059 \\
\hline$C_{24}$ & 0.0134 & -0.0895 & 0.0021 & -0.1120 & 0.0507 & 0 & 0.0292 & -0.0487 \\
\hline$C_{31}$ & 0.0084 & -0.0327 & 0.0047 & -0.0450 & 0.0224 & 0 & 0.0075 & -0.0404 \\
\hline$C_{32}$ & 0.0012 & -0.0550 & 0.0012 & -0.0553 & 0.0252 & 0 & 0.0090 & -0.0367 \\
\hline$C_{33}$ & 0.0024 & -0.0047 & 0.0036 & -0.0047 & 0.0022 & -0.0075 & 0.0006 & -0.0087 \\
\hline$C_{41}$ & 0.0130 & -0.0634 & 0.0370 & 0 & 0.0116 & -0.0572 & 0.0009 & -0.0820 \\
\hline$C_{42}$ & 0.0208 & 0 & 0.0114 & -0.0286 & 0.0055 & -0.0427 & 0.0075 & -0.0316 \\
\hline
\end{tabular}

TABLE 7: Prospective values of attributes of conservative schemes.

\begin{tabular}{|c|c|c|c|c|c|c|c|c|}
\hline \multirow{2}{*}{$\begin{array}{l}\text { Scheme } \\
\text { Criteria }\end{array}$} & \multicolumn{2}{|c|}{$x_{1}$} & \multicolumn{2}{|c|}{$x_{2}$} & \multicolumn{2}{|c|}{$x_{3}$} & \multicolumn{2}{|c|}{$x_{4}$} \\
\hline & $\begin{array}{c}\text { Positive } \\
\text { prospective } \\
\text { values }\end{array}$ & $\begin{array}{c}\text { Negative } \\
\text { prospective } \\
\text { values }\end{array}$ & $\begin{array}{c}\text { Positive } \\
\text { prospective } \\
\text { values }\end{array}$ & $\begin{array}{l}\text { Negative } \\
\text { prospective } \\
\text { values }\end{array}$ & $\begin{array}{c}\text { Positive } \\
\text { prospective } \\
\text { values }\end{array}$ & $\begin{array}{c}\text { Negative } \\
\text { prospective } \\
\text { values }\end{array}$ & $\begin{array}{c}\text { Positive } \\
\text { prospective } \\
\text { values }\end{array}$ & $\begin{array}{c}\text { Negative } \\
\text { prospective } \\
\text { values }\end{array}$ \\
\hline$\overline{C_{11}}$ & 0.0099 & 0 & 0.0057 & -0.0086 & 0 & -0.0223 & 0.0034 & -0.0119 \\
\hline$C_{12}$ & 0.0025 & -0.0328 & 0.0021 & -0.0325 & 0 & -0.0405 & 0.0180 & 0 \\
\hline$C_{13}$ & 0 & -0.0914 & 0.0406 & 0 & 0.0177 & -0.0394 & 0.0226 & -0.0315 \\
\hline$C_{21}$ & 0.0081 & 0 & 0.0055 & -0.0046 & 0.0042 & -0.0064 & 0 & -0.0181 \\
\hline$C_{22}$ & 0.0196 & 0 & 0.0152 & -0.0061 & 0 & -0.0442 & 0.0061 & -0.0253 \\
\hline$C_{23}$ & 0.0041 & 0 & 0.0025 & -0.0046 & 0.0014 & -0.0081 & 0.0030 & -0.0017 \\
\hline$C_{24}$ & 0.0054 & -0.0454 & 0.0006 & -0.0596 & 0.0271 & 0 & 0.0139 & -0.0218 \\
\hline$C_{31}$ & 0.0031 & -0.0135 & 0.0015 & -0.0198 & 0.0101 & 0 & 0.0027 & -0.0174 \\
\hline$C_{32}$ & 0.0003 & -0.0252 & 0.0003 & -0.0254 & 0.0116 & 0 & 0.0034 & -0.0154 \\
\hline$C_{33}$ & 0.0007 & -0.0013 & 0.0011 & -0.0013 & 0.0006 & -0.0023 & 0.0001 & -0.0027 \\
\hline$C_{41}$ & 0.0052 & -0.0299 & 0.0185 & 0 & 0.0045 & -0.0264 & 0.0002 & -0.0409 \\
\hline$C_{42}^{41}$ & 0.0092 & 0 & 0.0044 & -0.0114 & 0.0018 & -0.0186 & 0.0027 & -0.0129 \\
\hline
\end{tabular}

TABle 8: Revenue and loss ratio results and scheme ranking.

\begin{tabular}{ccccccc}
\hline & Scheme & $x_{1}$ & $x_{2}$ & $x_{3}$ & $x_{4}$ & Ranking \\
\hline \multirow{3}{*}{ Profit-loss ratio } & Risky parameters & 0.3613 & 0.5199 & 0.3801 & 0.3709 & $x_{2}>x_{3}>x_{4}>x_{1}$ \\
& Intermediate parameters & 0.3310 & 0.5328 & 0.3790 & 0.3731 & $x_{2}>x_{3}>x_{4}>x_{1}$ \\
& Conservative parameters & 0.2846 & 0.5625 & 0.3800 & 0.3810 & $x_{2}>x_{4}>x_{3}>x_{1}$ \\
\hline
\end{tabular}

makers regard enterprise $x_{3}$ as an alternative to enterprise $x_{2}$. In contrast, conservative decision-makers pay more attention to the overall level of the enterprise. In this case, the evaluation of enterprise $x_{3}$ is slightly inferior to that of enterprise $x_{4}$. By improving the prospect theory, the evaluation method proposed in this study reasonably analyzes the different ranking of enterprise evaluation by decisionmakers with different risk tendencies. This phenomenon is more consistent with the actual situation. Our evaluation model adequately accounts for the unknown weight, the dynamic nature of VE cooperation, and the relatively clear task orientation to scientifically evaluate potential partners for a VE. Such an evaluation system of VE partner capability can help enterprises choose partners who can learn from their strengths and compensate for their weaknesses, thus helping VEs avoid possible loopholes under different risk attitudes to maximize innovation revenue.

\section{Conclusion}

In the event of complex and changeable market demand, VE has the advantage of multiparty cooperation and can respond flexibly. However, different participants' backgrounds bring potential risks to the construction of VE. Therefore, careful partner selection is very important for the creation of VE. In this study, a multigranularity, 
hesitant fuzzy decision-making method for VE partner selection is proposed. According to the needs of enterprises, 4 main criteria and 12 subcriteria for VE partner selection are established. To avoid the influence of experts' subjective tendency weight, this study uses information entry and fuzzy theory to calculate the weight of the evaluation criteria when the weight of VE partner selection is unknown. Because the information in the alternative enterprise is not quantifiable and is incomplete, this study also uses the multigranularity fuzzy comprehensive evaluation method, which makes the positioning of a single alternative enterprise in the same industry more objective and accurate, and it is easier for the main enterprise to find suitable partners. To verify the scientificity and feasibility of the proposed criteria and methods for partner selection in VEs, a case study was conducted. The results show that the proposed criteria and methods have good practical application, and the decision-maker's risk attitude will affect the choice of partners. The above examples confirm that although the process of building a VE involves innovation risks, our approach to partner selection can enable such risks to be avoided and the allocation of innovation resources can be optimized to yield a stable VE. Our research not only considers the effective integration of internal and external technology, and knowledge resources in building VEs, but also covers the adaptability of the enterprise. To a certain extent, this method can be used as a structural model of VE partner selection. Besides, the methodology can also be improved according to the actual situation. For further research, a fuzzy questionnaire can be used for collecting data to prevent information bias.

\section{Data Availability}

The data used to support the findings of this study are included within the article.

\section{Conflicts of Interest}

The authors declare that there are no conflicts of interest regarding the publication of this paper.

\section{Authors' Contributions}

All authors contributed equally to this work.

\section{Acknowledgments}

The research was supported by The Major Soft Science Project of Shanxi Province (grant no. w20151020), The Soft Science Project of Shanxi Province (grant no. w20171015), Taiyuan University of Science and Technology Scientific Research Initial Funding (grant no. 20182037), Doctor Excellent Award Fund for work in Shanxi (grant no. 20192018), Scientific and Technological Innovation Programs of Higher Education Institutions in Shanxi (grant no. 2019L0649), and Applied Basic Research Project of Shanxi Province (grant no. 201901D211288).

\section{References}

[1] Z.-J. Wang, X.-F. Xu, and D.-C. Zhan, "Genetic algorithm for collaboration cost optimization-oriented partner selection in virtual enterprises," International Journal of Production Research, vol. 47, no. 4, pp. 859-881, 2009.

[2] W. Reithofer and G. Naeger, "Bottom-up planning approaches in enterprise modelling-the need and the state of the art," Computers in Industry, vol. 33, no. 2-3, pp. 223-235, 1997.

[3] F. Lu, M. Huang, and X. Wang, "Risk management model and algorithm of virtual enterprise baesed on stochastic programming," Systems Engineering, vol. 28, no. 2, pp. 36-43, 2010.

[4] H. Gou, B. Huang, W. Liu, and X. Li, "A framework for virtual enterprise operation management," Computers in Industry, vol. 50, no. 3, pp. 333-352, 2003.

[5] J. Gan, Y. Zhang, Y. Hu, and S. Liu, “The cooperation partner selection of private sector under public-private-partnership projects: an improved approach under group decisionmaking based on FRS, SAW, and integrated objective/subjective attributes," Discrete Dynamics in Nature and Society, vol. 2018, Article ID 4261026, 8 pages, 2018.

[6] V. G. Venkatesh, A. Zhang, E. Deakins, S. Luthra, and S. Mangla, "A fuzzy AHP-TOPSIS approach to supply partner selection in continuous aid humanitarian supply chains," Annals of Operations Research, vol. 283, no. 1-2, pp. 15171550, 2019.

[7] J. A. Byrne, "The virtual corporation," Business Week, vol. 8, pp. 98-103, 1993.

[8] S. H. Han, K. H. Chin, and M. J. Chae, "Evaluation of CITIS as a collaborative virtual organization for construction project management," Automation in Construction, vol. 16, no. 2, pp. 199-211, 2007.

[9] C. Petrie and C. Bussler, "Service agents and virtual enterprises: a survey," IEEE Internet Computing, vol. 7, no. 4, pp. 68-78, 2003.

[10] J. Mun, M. Shin, K. Lee, and M. Jung, "Manufacturing enterprise collaboration based on a goal-oriented fuzzy trust evaluation model in a virtual enterprise," Computers \& Industrial Engineering, vol. 56, no. 3, pp. 888-901, 2009.

[11] X. Hu, Y. Tang, and C. Li, "Task-oriented virtual enterprise recurrent alignment governance mechanisms," Systems Engineering-Theory \& Practice, vol. 27, no. 11, pp. 34-42, 2007, in Chinese.

[12] A. Gunasekaran, K. Lai, and T. Edwincheng, "Responsive supply chain: a competitive strategy in a networked economy," Omega, vol. 36, no. 4, pp. 549-564, 2008.

[13] A. Arafa and W. H. Elmaraghy, "Manufacturing strategy and enterprise dynamic capability," CIRP Annals, vol. 60, no. 1, pp. 507-510, 2011.

[14] R. Hofstetter, J. Z. Zhang, and A. Herrmann, "Successive open innovation contests and incentives: winner-take-all or multiple prizes?" Journal of Product Innovation Management, vol. 35, no. 4, pp. 492-517, 2018.

[15] J. Yoon, W. Seo, B.-Y. Coh, I. Song, and J.-M. Lee, "Identifying product opportunities using collaborative filtering-based patent analysis," Computers \& Industrial Engineering, vol. 107, pp. 376-387, 2017.

[16] B. Lv and X. Qi, "Research on partner combination selection of the supply chain collaborative product innovation based on product innovative resources," Computers \& Industrial Engineering, vol. 128, pp. 245-253, 2019.

[17] S. Yayavaram, M. K. Srivastava, and M. Sarkar, "Role of search for domain knowledge and architectural knowledge in 
alliance partner selection," Strategic Management Journal, vol. 39, no. 8, pp. 2277-2302, 2018.

[18] P. Ávila, A. Mota, A. Pires, J. O. Bastos, G. Putnik, and J. Teixeira, "Supplier's selection model based on an empirical study," Procedia Technology, vol. 5, pp. 625-634, 2012.

[19] S. S. Msanjila and H. Afsarmanesh, "Trust analysis and assessment in virtual organization breeding environments," International Journal of Production Research, vol. 46, no. 5, pp. 1253-1295, 2008.

[20] N. Wu and P. Su, "Selection of partners in virtual enterprise paradigm," Robotics and Computer-Integrated Manufacturing, vol. 21, no. 2, pp. 119-131, 2005.

[21] F. Ye and Y.-N. Li, "Group multi-attribute decision model to partner selection in the formation of virtual enterprise under incomplete information," Expert Systems with Applications, vol. 36, no. 5, pp. 9350-9357, 2009.

[22] Y. Dorfeshan, S. M. Mousavi, V. Mohagheghi, and B. Vahdani, "Selecting project-critical path by a new interval type-2 fuzzy decision methodology based on MULTIMOORA, MOOSRA and TPOP methods," Computers \& Industrial Engineering, vol. 120, no. 1, pp. 160-178, 2018.

[23] J. Crispim, N. Rego, and J. Pinho de Sousa, "Stochastic partner selection for virtual enterprises: a chance-constrained approach," International Journal of Production Research, vol. 53, no. 12, pp. 3661-3677, 2015.

[24] W. H. Ip, M. Huang, K. L. Yung, and D. Wang, "Genetic algorithm solution for a risk-based partner selection problem in a virtual enterprise," Computers \& Operations Research, vol. 30, no. 2, pp. 213-231, 2003.

[25] D. Choudhary and R. Shankar, "An STEEP-fuzzy AHPTOPSIS framework for evaluation and selection of thermal power plant location: a case study from India," Energy, vol. 42, no. 1, pp. 510-521, 2012.

[26] C. L. Hwang and K. Yoon, Multiple Attribute Decision Making: Methods and Applications A State-of-the-Art Survey, Springer-Verlag, Berlin, Germany, 1981.

[27] F. Ye, "An extended TOPSIS method with interval-valued intuitionistic fuzzy numbers for virtual enterprise partner selection," Expert Systems with Applications, vol. 37, no. 10, pp. 7050-7055, 2010.

[28] Z. Jia and Y. Zhang, "Interval-valued intuitionistic fuzzy multiple attribute group decision making with uncertain weights," Mathematical Problems in Engineering, vol. 2019, Article ID 5092147, 9 pages, 2019.

[29] J. Zhai, X. Wang, S. Zhang, and S. Hou, "Tolerance rough fuzzy decision tree," Information Sciences, vol. 465, pp. 425-438, 2018.

[30] S.-J. Chuu, "Evaluating the flexibility in a manufacturing system using fuzzy multi-attribute group decision-making with multi-granularity linguistic information," The International Journal of Advanced Manufacturing Technology, vol. 32, no. 3-4, pp. 409-421, 2007.

[31] Z. Zhang and X. Chu, "Fuzzy group decision-making for multi-format and multi-granularity linguistic judgments in quality function deployment," Expert Systems with Applications, vol. 36, no. 5, pp. 9150-9158, 2009.

[32] S. Sardari, M. Eftekhari, and F. Afsari, "Hesitant fuzzy decision tree approach for highly imbalanced data classification," Applied Soft Computing, vol. 61, pp. 727-741, 2017.

[33] J. Rabcan, V. Levashenko, E. Zaitseva, M. Kvassay, and S. Subbotin, "Application of fuzzy decision tree for signal classification," IEEE Transactions on Industrial Informatics, vol. 15, no. 10, pp. 5425-5434, 2019.

[34] E. B. Tirkolaee, A. Mardani, Z. Dashtian, M. Soltani, and G. Weber, "A novel hybrid method using fuzzy decision making and multi-objective programming for sustainablereliable supplier selection in two-echelon supply chain design," Journal of Cleaner Production, vol. 250, pp. 1-59, 2020.

[35] H. Dinçer, S. Yüksel, and L. Martínez, "Balanced scorecardbased analysis about European energy investment policies: a hybrid hesitant fuzzy decision-making approach with quality function deployment," Expert Systems with Applications, vol. 115, pp. 152-171, 2019.

[36] G. Büyüközkan and S. Güleryüz, "A new integrated intuitionistic fuzzy group decision making approach for product development partner selection," Computers \& Industrial Engineering, vol. 102, pp. 383-395, 2016.

[37] S. Liu, Y. Hu, and Y. Zhang, "Supply chain partner selection under cloud computing environment: an improved approach based on BWM and VIKOR," Mathematical Problems in Engineering, vol. 2018, Article ID 7012827, 11 pages, 2018.

[38] J. Hagedoorn and G. Duysters, "External sources of innovative capabilities: the preferences for strategic alliances or mergers and acquisitions," Journal of Management Studies, vol. 39, no. 2, pp. 167-188, 2002.

[39] J. A. C. Baum, R. Cowan, and N. Jonard, "Network-independent partner selection and the evolution of innovation networks," Management Science, vol. 56, no. 11, pp. 20942110, 2010.

[40] E. Naveh, "The effect of integrated product development on efficiency and innovation," International Journal of Production Research, vol. 43, no. 13, pp. 2789-2808, 2005.

[41] K. Rangus and M. Černe, "The impact of leadership influence tactics and employee openness toward others on innovation performance," RédD Management, vol. 49, no. 2, pp. 168-179, 2019.

[42] W. Tan, Y. Xu, W. Xu et al., "A methodology toward manufacturing grid-based virtual enterprise operation platform," Enterprise Information Systems, vol. 4, no. 3, pp. 283-309, 2010.

[43] M. Sköld and C. Karlsson, "Technology sharing in manufacturing business groups," Journal of Product Innovation Management, vol. 29, no. 1, pp. 113-124, 2012.

[44] J. J. Kanet, W. Faisst, and P. Mertens, "Application of information technology to a virtual enterprise broker: the case of Bill Epstein," International Journal of Production Economics, vol. 62, no. 1-2, pp. 23-32, 1999.

[45] C. Wei and H. Liao, "A multigranularity linguistic group decision-making method based on hesitant 2-tuple sets," International Journal of Intelligent Systems, vol. 31, no. 6, pp. 612-634, 2016.

[46] L. A. Zadeh, "Fuzzy sets," Information and Control, vol. 8, no. 3, pp. 338-353, 1965.

[47] Z. Xu and M. Xia, "Hesitant fuzzy entropy and cross-entropy and their use in multiattribute decision-making," International Journal of Intelligent Systems, vol. 27, no. 9, pp. 799-822, 2012.

[48] J. Zhu, Z. Ma, H. Wang, and Y. Chen, "Risk decision-making method using interval numbers and its application based on the prospect value with multiple reference points," Information Sciences, vol. 385-386, pp. 415-437, 2017.

[49] Y. M. Wang, C. P. Que, and Y. X. Lan, "Hesitant fuzzy topsis multi-attribute decision method based on prospect theory," Control and Decision, vol. 32, no. 5, pp. 864-870, 2017, in Chinese.

[50] Y. Liu, F. Jeffrey, and S. Liu, "Multi-objective grey target decision-making based on prospect theory," Control and Decision, vol. 28, no. 3, pp. 345-350, 2013, in Chinese.

[51] A. Tversky and D. Kahneman, "Advances in prospect theory: cumulative representation of uncertainty," Journal of Risk and Uncertainty, vol. 5, no. 4, pp. 297-323, 1992. 
[52] D. Bernoulli, "Exposition of a new theory on the measurement of risk," Econometrica, vol. 22, no. 1, p. 23, 1954.

[53] J. Ma and X. Sun, "Modified value function in prospect theory based on utility curve," Information \& Control, vol. 40, no. 4, pp. 501-506, 2011, in Chinese.

[54] J. M. Zeng, "An experimental test on cumulative prospect theory," Journal of Jinan University, vol. 2007, no. 1, pp. 47-50, 2007, in Chinese.

[55] J. W. Gao and F. J. Guo, "Intuitionistic fuzzy stochastic multicriteria decision-making method based on modified prospect theory," Control \& Decision, vol. 34, no. 2, pp. 317-324, 2019, in Chinese. 